Revue d'histoire de l'enfance « irrégulière »

Le Temps de l'histoire

19 | 2017

Abandon d'enfants et parents abandonneurs, $\mathrm{XIX} \mathrm{X}^{\mathrm{e}} \mathrm{XX \textrm {I } ^ { \mathrm { e } }}$ siècles

\title{
Éduquer sous contrainte
}

Jacques Bourquin

\section{(2) OpenEdition}

Journals

Édition électronique

URL : https://journals.openedition.org/rhei/4100

DOI : 10.4000/rhei.4100

ISSN : $1777-540 \mathrm{X}$

Éditeur

Presses universitaires de Rennes

Édition imprimée

Date de publication : 22 novembre 2017

Pagination : 219-221

ISBN : 978-2-7535-6467-7

ISSN : $1287-2431$

Référence électronique

Jacques Bourquin, « Éduquer sous contrainte », Revue d'histoire de l'enfance « irrégulière » [En ligne], 19 | 2017, mis en ligne le 22 novembre 2017, consulté le 08 septembre 2021. URL : http://

journals.openedition.org/rhei/4100; DOI : https://doi.org/10.4000/rhei.4100

(c) PUR 


\section{Éduquer sous contrainte. Une sociologie de la justice des mineurs Nicolas Sallée \\ 2016}

Paris, EHESS, collection « Cas de figure », 227 p., ISBN : 9782713225376.

Nicolas Sallée est sociologue, il enseigne à l'université de Montréal. Il a soutenu sa thèse de doctorat en 2012, à Paris, sous la direction de Jacques Commailles, sur la protection judiciaire des mineurs en France et son évolution actuelle qui privilégie la référence à la notion de contrainte pénale. Il souligne, dans son ouvrage, le lien entre la protection et la responsabilité. Lordonnance du 2 février 1945 sur l'enfance délinquante était-elle, à son origine, en phase avec la pénalité? Dans une approche historique, il montre combien les mesures de protection et d'éducation, dont le texte de 1945 était porteur, apportaient une réelle primauté sur la sanction pénale. Il rappelle à ce sujet que dans ce texte, celles-ci n'étaient possibles qu’à «titre exceptionnel » sur décision du juge des enfants. Nicolas Sallée montre que le droit pénal des mineurs s'est construit en France comme un droit en tension entre la reconnaissance d'un besoin de protection des mineurs et la conservation d'un système juridique de la responsabilité pénale. On s'interrogea beaucoup en 1944-1945, pour savoir si la toute nouvelle direction de l'Éducation surveillée, issue de l'Administration pénitentiaire, devait relever de la Santé ou de la Justice; c'est la Justice qui l'emporta. La nouvelle direction s'inscrit toutefois dans un projet de rééducation avec une priorité accordée à l'observation et à la formation professionnelle, les éducateurs apparaissent dès les toutes premières années de l'Éducation surveillée, leur formation et les activités de recherche qui se mettent en place vont très vite privilégier les conceptions constitutionnalistes de la psychiatrie infantile portées par Georges Heuyer et les conceptions psychologiques, d'orientation psychanalytique portées par Daniel Lagache. Les éducateurs vont s'initier aux sciences humaines et sociales.

Concernant les jeunes délinquants, on insiste, dans la démarche éducative, sur l'importance du rôle de l'affectif et du milieu, en privilégiant un regard sociologisant sur la délinquance juvénile. Le jeune délinquant, précise N. Sallée, est moins considéré " comme un anormal à rééduquer " que comme " un être souffrant qu'il convient de réparer ». Les travaux du Centre de recherche et de formation de l'Éducation surveillée, à Vaucresson, accompagnent ces 
orientations. En 1958, une nouvelle prérogative apparaît, l'Éducation surveillée va avoir compétence pour s'occuper des jeunes en danger, non délinquants, qui vont relever du juge des enfants. On parle de prédélinquance, la pratique éducative s'inscrit dans une démarche préventive, la notion de situation sociale et familiale du jeune devient centrale, on assiste au développement des interventions éducatives en milieu ouvert aussi bien auprès des mineurs en danger que des mineurs délinquants dont les problématiques sont souvent voisines.

En 2009, la Protection judiciaire de la jeunesse (PJJ) perd cette compétence en matière d'enfants en danger, les éducateurs vivent très mal cette perte qui rétrécit le champ de leurs activités et qu'ils ressentent, selon N. Sallée, comme une reprise en main par le judiciaire et une marginalisation sociale dont l'enfance délinquante va désormais être l'objet. Il y a, précise l'auteur, une évolution vers une politique éducative de la contrainte. La justice des mineurs ou plutôt son esprit seraient-ils en danger? Déjà, dans les années 1990, cette évolution s'annonçait avec l'ouverture des centres éducatifs renforcés (CER) puis un peu plus tard des centres éducatifs fermés (CEF) et des établissements pénitentiaires pour mineurs (EPM); il y a une focalisation de plus en plus grande sur l'acte délinquant au détriment de l'attention portée à la personnalité de son auteur. À la pensée sociale et éducative d'une responsabilité collective qui primait en 1945, se substitue, constate N. Sallée, une pensée néolibérale d'une justice punitive. La législation concernant les mineurs délinquants après la loi de 1995 sur les peines planchers pour les mineurs récidivistes et jusqu'aux lois de 2002 et 2007 va dans le sens de rompre avec la philosophie de la réhabilitation qui prédominait. Dans la seconde partie de son ouvrage, "Les éducateurs au travail », N. Sallée centre son propos sur les contradictions dans lesquelles se trouvent les éducateurs. Il évoque leurs pratiques et le poids progressif de la contrainte pénale qui, au risque d'une uniformisation de celles-ci, renforce le lien entre travail éducatif et contrôle judiciaire. Les centres éducatifs fermés, lieux d'enfermement, sans être des prisons, renvoient à un retour des conceptions de plus en plus comportementalistes dont l'Éducation surveillée s'était éloignée dès les années 1970. Dans sa conclusion, N. Sallée, tout en considérant que la justice pénale des mineurs n'est jamais sortie du droit pénal, note que l'Éducation surveillée et le métier d'éducateur ont opéré, dans la seconde partie $\mathrm{du} \mathrm{Xx}^{\mathrm{e}}$ siècle, une sorte de "despécialisation de la délinquance juvénile », l'acte délinquant, sans être ignoré, était surtout perçu comme le symptôme d'une 
situation sociale et familiale de danger. Ce mouvement a donné lieu dans les années 1990, à diverses réflexions juridiques, éducatives et même psychiatriques, qui justifient progressivement l'usage éducatif de la norme pénale dans « une économie morale fondée sur l'impératif de la responsabilisation par rapport à l'acte ». Le recentrage de l'activité pédagogique sur l'acte accroît, dans l'action éducative, le poids de la responsabilisation du jeune qui fait de la contrainte un élément central du traitement du jeune délinquant. Ceci s'inscrit, pour N. Sallée, dans une dynamique plus générale depuis les années 1990, marquée par « un transfert des risques sociaux vers l'individu, un outil privilégié participant au contrôle et à la responsabilisation des populations les plus marginalisées ". Le rôle de l'éducateur n'en est que plus ambigu, jusqu'à remettre en cause son autonomie professionnelle en développant un modèle éducatif où la "responsabilisation renoue avec les vieilles utopies disciplinaires». L'éducateur que je fus et la connaissance que j'ai de cette histoire me font pleinement adhérer aux analyses de N. Sallée.

Jacques Bourquin

\section{Le Centre international de l'enfance (1949-1997). \\ Des archives à l'histoire \\ Yves Denéchère et Patrice Marcilloux (dir.) \\ 2016}

Presses universitaires de Rennes, Rennes, 2016, 202 p.,

ISBN : 9782753548688.

Cet ouvrage est issu d'un colloque qui s'est tenu à Angers en 2014. Pourquoi à Angers alors que le Centre international de l'enfance avait son siège à Longchamp? Parce que l'université du Maine-et-Loire a participé au sauvetage des archives et du fonds documentaire de cette institution qui semblaient promis au pilon. Le livre rassemble des textes de natures très différentes comme tous les actes de manifestations scientifiques où se croisent les historiens et les acteurs/témoins: les articles d'historiens et les présentations d'archives voisinent avec des témoignages.

Il s'ouvre, après une introduction qui explicite la démarche et les objectifs de cette rencontre, sur une biographie quelque peu hagiographique et peu problématisée du fondateur du Centre international de l'enfance, Robert Debré (Sedan 1882-Paris 1978), par son petit-fils. 